\title{
Ethical Aspects of Sexuality in Old Age
}

\author{
Smit Parmar \\ Consultant Psychiatrist, Neuropsychiatric Care Centre, Valsad \\ Corresponding Author: Smit Parmar \\ E-mail: parmarsmit99@gmail.com
}

\begin{abstract}
Introduction
Human sexuality is recognized as a fundamental driving force but is frequently misunderstood and particularly in the elders it is neglected [1]. A marked increase in life expectancy over the past century has meant that individuals over the age of 65 years form an increasingly large proportion of our population [2]. Human beings are actually never too old to enjoy a happy and healthy sex life. Despite this, many people, young and old alike, are astounded at the idea of people remaining sexually active in their sixties and beyond. It is frequently assumed that elder persons lose their sexual desires or that they are physically unable to perform. For the elders, the ability to remain sexually active is a major concern in their lives. Fear about the loss of sexual prowess in older males is common. Older women also express sexual desire, but may fear their interest is undignified and disgraceful. Some elder persons may even freely accept their interests in sex, but their children or grandchildren may disapprove, making them feel guilty. The elder often view sexuality as an expression of passion, affection, admiration, and loyalty, a renewal of romance, a general affirmation of life, especially the expression of joy and a continuing opportunity for growth and experience. In addition, sexual activity is a means for the elder to affirm physical functioning, to maintain a strong sense of identity and establish self-confidence, and to prevent anxiety. It remains a mode of pure physical pleasure as well. However, not all elder persons have positive attitudes about sexuality. Like all persons, elders may experience sexual dysfunction due to boredom, fear, fatigue, grief, or other factors (e.g., intrinsically low sexual desire, physical disability). Sexuality in the elder is particularly affected by problems that are common in this age group, for example, depression, medical disorders, or incapacitation or death of a partner [3].
\end{abstract}

\section{The concept of ethics}

Ethics or moral philosophy is a branch of philosophy that "involves systematizing, defending, and recommending concepts of right and wrong behaviour" [4]. The field of ethics, along with aesthetics, concerns matter of value; these fields comprise the branch of philosophy called axiology [5]. Ethics seeks to resolve questions of human morality by defining concepts such as good and evil, right and wrong, virtue and vice, justice and crime. As a field of intellectual inquiry, moral philosophy is related to the fields of moral psychology, descriptive ethics, and value theory [6].

\section{Ethics, sexuality and old age}

Availability of partners plays a major role in how older adults experience sexuality. It is well documented that the majority of women outlive the majority of men in the United States. In contrast to older women, older men have significantly more opportunities to pursue opposite-sex relationships [7]. Approximately four out of five women who are seventy-five or older do not have a male sexual partner. In contrast, over $60 \%$ of the men in this age group do have a partner (AARP). The consequences of this gender gap have both personal and public health ramifications. With the advent of prescription drugs (for example, Viagra) that aid male erections, older men are more sexually active than in past generations. Drug-enhanced stamina paired with the gender gap makes it likely for partner-sharing to occur, such that each older man may have two or three female sexual partners who are within his peer group. Public health problems are magnified when older men 
seek out the services of prostitutes and bring sexually transmitted diseases, including HIV, back to their senior partners [8]. The problems in older aged people increases when they have dementia. When a spouse is affected by dementia, moral and ethical views eventually can come into play. Healthy partners, more and more frequently, are going outside of marriage as the unmet emotional needs begin to increase. In addition to their own feelings of guilt, disapproving family members, friends, or physicians with little awareness of how to deal with this sensitive aspect of life with dementia may exacerbate the problem [9]. If relationships are the private arena in the struggle with sexuality and dementia, then long-term care is the public arena. With increasing frequency, assisted-living and skilled-care nursing facilities as well as older adults' family homes are walking a blurring line between guarding against neglect and abuse of residents, particularly those with dementia [9]. Specifically, when it comes to sexuality in long term care, not permitting residents to express their sexuality constitutes neglect, while failing to protect residents from unwanted sexual expression by another constitutes abuse. Abuse may range from criminal predation of a staff member or resident to a simple case of mistaken identity in a confused dementia patient.

Many of the staff members are young and may have little experience that prepares them for sexual behaviours in confused patients. Families may have differing religious or cultural backgrounds, giving way to differing views. The demand to fill nursing home beds may exert pressure from corporate mandates on facility administrators, encouraging the admission of prospective new residents with known inappropriate sexual behaviours that are likely to create difficulties [9].

Intimacy and sexuality expressed by nursing home residents with dementia remains an ethically sensitive issue for care facilities, nursing staff and family members. Dealing with residents' sexual longings and behaviour is extremely difficult, putting a burden on the caregivers as well as on the residents themselves and their relatives [10].

Ethical dilemma also occurs for use of drugs to increase or decrease sexual urge in old age. One study found that overall sexual activity showed a declining course with increasing age but still continued in individuals above 50 years of age. They also found that women were less interested and also less involved in both coital as well as non-coital activities. Sexual function is generally better in an active and working lifestyle in old age. Increasing age generally comes with reduction in quality of erection, ejaculate volume, vaginal lubrication, orgasmic pleasure and overall sexual functioning. Most individuals do not seem to be distressed with these changes. They frequently have more incidence of co-morbid illness in cases with worsened sexual function and sexual activity. People with old age have significant increase in the time required for sexual arousal. This study also quoted that love and intimacy stayed the same for majority of their subjects [11].

Moral and cultural values can interfere with the normal process of sexuality in old age. A sexually active old age female may want to have some drugs that can help her subside her sexuality as she may find it culturally inappropriate for her age. The ethical dilemma here falls on the doctor. Respecting the patients' autonomy takes priority but prescribing drugs or undergoing any kind of medical procedures has at old age has its own negative implications. Taking the high levels of comorbidity into account it might be as well be risky. For example, Sildenafil citrate has been shown to be an effective and well-tolerated oral agent for treating ED in the general population of adult men with ED of broad-spectrum aetiology. Elderly men are more likely to have concomitant medical problems than the general population of men with ED [12]. There is an incidence of $18 \%$ headache, $8 \%$ flushing, $8 \%$ dyspepsia, $5 \%$ nasal congestion and $2 \%$ visual changes of adverse effects among the older age group. No overt cardiovascular events are reported. So, sildenafil is an effective agent in elderly men, but it had a lower efficacy rate with increasing age, especially in men aged $>80$ years [13].

Sometimes when a person in old age, especially with dementia is sexually active, there are concerns about whether the person has the mental capacity to consent. This may be a concern both in existing relationships and in new relationships. All health and social care staff have a vital role to play in protecting vulnerable people from abuse and exploitation [14]. However, it is essential to be aware that the first statutory principle of the Mental Capacity Act 2005 is that 'a person must be assumed to have capacity unless it is established that he lacks capacity'. A diagnosis of dementia alone does not automatically mean that a person lacks capacity to consent to sex [14]. The Mental Capacity Act also tells us that a person must be given help with decision-making. This could 
involve developing some awareness, if possible, of a person's past sexual preferences and habits and reminding them of wishes they have communicated previously. It also needs to be recognised that consent to sex will often be communicated non-verbally rather than verbally. Patients with dementia cannot be assumed to have impaired capacity. Even a patient with moderate or severe dementia, with obviously impaired capacity may still be able to indicate a choice and show some understanding. Four key components of decision-making in a capacity evaluation include understanding, communicating a choice, appreciation, and reasoning. Assessment of capacity requires a direct interview with the patient using open-ended questions and may include both informal and formal approaches depending on the situation and the context. A baseline cognitive evaluation with a simple test to assess executive function is often useful in capacity evaluation. All capacity evaluations are situation specific, relating to the particular decision under consideration, and are not global in scope. The clinician needs to spend adequate time with the patient and the family allaying their anxieties and also consider the sociocultural context. The area of capacity has considerable overlap with law and the clinician treating patients with dementia should understand the complexities of assessment and the implications of impaired capacity. It is also essential that the clinician be well informed and keep meticulous records. It is crucial to strike a balance between respecting the patient autonomy and acting in his/her best interest [15]. If somebody does have the capacity to consent to engage in a sexual relationship with another consenting adult, then they have the right to do so regardless of whether other people approve and their privacy must be respected [14].

Older aged people with LGBTQ face different issues. Older LGBTQ people are marginalised by: a) younger LGBT people, because of ageism; and b) by older age social networks because of homophobia, biphobia, transphobia, heteronormativity (the assumption that everyone is heterosexual, heterosexism (the privileging of heterosexuality), prejudice and discrimination towards LGBT people. Stigma against sexual expression in LGBTQ older adults may cause concealment of sexual orientation from family or care providers due to fears of rejection [16]. When compared with their heterosexual cisgender (non-transgender) counterparts, LGBTQ+ older adults are more likely to delay or not seek medical care, often due to fear of real or perceived discrimination from healthcare providers [17].

This topic is rarely talked about or discussed in the public. A geriatric person may have or may not be sexually active but the ethical aspects associated with it need to be discussed more vividly.

\section{REFERENCES}

1. Walker BL. Sexuality and the elderly: A research guide. Annotated ed. Westport, CT: Greenwood Press; 1997.

2. Tien-Hyatt JL. Self-perceptions of aging across cultures: Myth or reality? Int J Aging Hum Dev 1986-1987;24:129-48.

3. Pfeiffer E, Verwoerdt A, Davis GC. Sexual behavior in middle life. Am J Psychiatry $1972 ; 128: 1262-7$.

4. Ludger V, Susanne K, Franz-Josef E. Die Literaturrundschau. Communicatio Socialis. 2015.

5. Internet Encyclopedia of Philosophy. [cited 2021May24]. Available from: ttps://iep.utm.edu/ethics/

6. Flexner SB. Random House unabridged dictionary. New York: Random House; 1993.

7. Carr D. The Desire to Date and Remarry among Older Widows and Widowers. J Marriage Family 2004;66:1051-68.

8. Nack A. Sexuality over the Lifespan--Social Trends Pose Moral Dilemmas for Communities of Faith. Intersections 2006;22:5

9. Wornell D. Sexuality and dementia: compassionate and practical strategies for dealing with unexpected or inappropriate behaviors. 2nd ed. Vol. 7. New York, NY: Demos Health; 2014.

10. Mahieu L, Anckaert L, Gastmans C. Intimacy and Sexuality in Institutionalized Dementia Care: Clinical-Ethical Considerations. Health Care Anal 2017;25(1):52-71.

11. Kalra G, Subramanyam A, Pinto C. Sexuality: desire, activity and intimacy in the elderly. Indian J Psychiatry 2011;53(4):300-6. 
12. Fujisawa M, Sawada K. Clinical efficacy and safety of sildenafil in elderly patients with erectile dysfunction. Arch Androl 2004;50(4):255-60.

13. Müller A, Smith L, Parker M, Mulhall JP. Analysis of the efficacy and safety of sildenafil citrate in the geriatric population. BJU Int 2007;100(1):117-21.

14. The expression of sexuality in dementia [Internet]. Social Care Institute for Excellence. [cited 2021May24]. Available from: https://www.scie.org.uk/dementia/living-with-dementia/difficultsituations/sexual-expression.asp

15. Hegde S, Ellajosyula R. Capacity issues and decision-making in dementia. Ann Indian Acad Neurol. 2016;19(Suppl 1):S34-9.

16. Srinivasan S, Glover J, Tampi RR, Tampi DJ, Sewell DD. Sexuality and the Older Adult. Curr Psychiatry Rep. 2019;21(10):97-108.

17. Alvarado LA, Dorsen C, Jere C, Woerner L, Jones E, Miner SM. Designing a Program to Serve Older Adult LGBTQ+ Populations in Home Healthcare. Home Healthcare Now 2020;38(4):20914.

Acknowledgements: Nil

Funding: Nil

Conflict of interest: Nil 